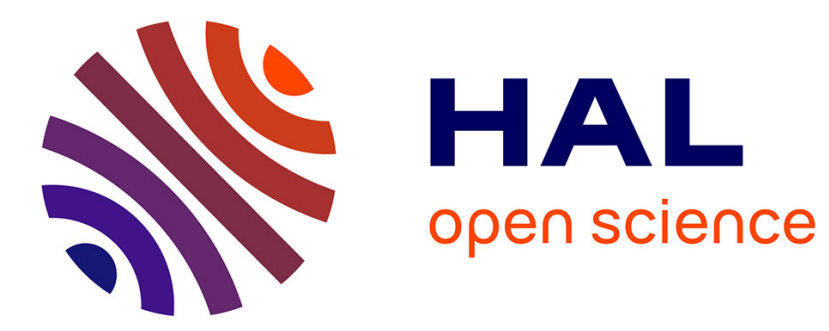

\title{
Silicon nanowires as negative electrode for lithium-ion microbatteries
}

\author{
Barbara Laik, Laurent Eude, Jean Pierre Pereira-Ramos, Costel Sorin \\ Cojocaru, Didier Pribat, Emmanuelle Rouvière
}

\section{To cite this version:}

Barbara Laik, Laurent Eude, Jean Pierre Pereira-Ramos, Costel Sorin Cojocaru, Didier Pribat, et al.. Silicon nanowires as negative electrode for lithium-ion microbatteries. Electrochimica Acta, 2008, 53 (17), pp.5528-5532. 10.1016/j.electacta.2008.02.114 . hal-00796266

\section{HAL Id: hal-00796266 https://hal.science/hal-00796266}

Submitted on 2 Mar 2013

HAL is a multi-disciplinary open access archive for the deposit and dissemination of scientific research documents, whether they are published or not. The documents may come from teaching and research institutions in France or abroad, or from public or private research centers.
L'archive ouverte pluridisciplinaire HAL, est destinée au dépôt et à la diffusion de documents scientifiques de niveau recherche, publiés ou non, émanant des établissements d'enseignement et de recherche français ou étrangers, des laboratoires publics ou privés. 


\title{
Electrochimica Acta
}

53 (2008) 5528-5532

DOI:

http://dx.doi.org/10.1016/j.electacta.2008.02.114

\section{Silicon nanowires as negative electrode for lithium-ion microbatteries}

\author{
Barbara Laik $^{\text {a,* }}$, Laurent Eude ${ }^{\text {, }}$, Jean-Pierre Pereira-Ramos ${ }^{a}$, Costel Sorin Cojocaru ${ }^{\text {, }}$, Didier Pribat \\ b, Emmanuelle Rouvière ${ }^{c}$ \\ ${ }^{a}$ Institut de Chimie et des Matériaux Paris Est, ICMPE/GESMAT, UMR 7182 CNRS-Université Paris XII, 2 rue Henri Dunant, 94320 Thiais, France \\ ${ }^{\mathrm{b}}$ Laboratoire de Physique des Interfaces et Couches Minces, LPICM, UMR 7647 École Polytechnique-CNRS, Route de Saclay, 91128 Palaiseau Cedex, France \\ ${ }^{c}$ Laboratoire des Composants Hybrides, LCH, CEA-DRT/LITEN/DTNM, 17 rue des martyrs, 38054 Grenoble Cedex, France
}

\section{KEYWORDS:}

Lithium batteries,

Silicon,

Si nanowires,

Thin films

\section{Introduction}

The current commercial lithium-ion secondary batteries are the most widely used because of their higher energy density, their higher operating voltages and their lower self-discharge [1,2]. They are based on an anode made of graphitic carbon or other carbonaceous materials that present on the one hand the advantage to be cheap and on the other hand interesting electrochemical properties such as a low and flat working voltage and a good cycleability. However, the maximal insertion of one lithium ion for six carbon atoms leads to a theoretical capacity limited to $372 \mathrm{mAh} \mathrm{g}^{-1}$, which is relatively low. In order to satisfy to the increasingly demand for new compact and modern portable electronic devices, both the active materials in the cathode and the anode should be replaced by new materials.

Concerning the anodic materials, metals, metalloids and semiconductors such as $\mathrm{Sn}, \mathrm{Al}, \mathrm{Sb}$ and $\mathrm{Si}$ which can make alloys with lithium, are attractive alternatives to graphite due to their low cost and high storage energy density. Theoretical specific capacities more than ten times higher than with carbon can be obtained. However, the structural changes and a large volume expansion associated with lithium insertion, which can rise to more than $300 \%$ (whereas it is below $10 \%$ for $\mathrm{LiC}_{6}$ ) [3], limit the ability of these materials to cycle with high efficiency. Indeed, successive charge-discharge cycles lead to mechanical stresses in the electrode and finally to the destruction of its structural integrity and to the consequent loss of electronic particle to particle contact [4-6].

Among the above materials, silicon has the highest specific capacity since it is capable to form compounds which can insert up to 4.2 lithium per silicon. Its theoretical capacity is as high as $4200 \mathrm{mAh} \mathrm{g}^{-1}$ [7-9]. Moreover, the electrochemical curves obtained during the insertion/deinsertion of lithium into/from silicon are roughly flat as it is with graphite and in a low voltage range $0.4 / 0.02 \mathrm{~V}$, that makes Si very attractive [10-12]. Li alloying in crystalline $\mathrm{Si}$ is known to induce the formation of new intermetallic phases leading to inhomogeneous volume expansions in the two-phase regions and then to cracking and pulverization of the material $[13,14]$. As a consequence of this cracking, there is a loss of inter-particles electrical contact inducing a significant capacity decline. Therefore, the loss of electric contact is still a crucial hurdle that must be overcome in order to improve the cycleability during further alloying/de-alloying reactions.

Different ways have been tested to solve the problem of cycle life by coating the surface of $\mathrm{Si}$ with various conducting materials [15-17], by modifying the substrate surface properties with adapted treatments to improve the adhesion of the Si film $[18,19]$ or by using for instance composite electrodes in which secondary components (carbon, copper, tin, etc.) are added to obtain mechanical stability, to enhance the electronic conduction or to improve the ionic or atomic transport [14,20-23]. 

Another trend for improving the cycle life of $\mathrm{Si}$ consists in using amorphous Si. Indeed in amorphous alloys the volume expansion on $\mathrm{Li}$ insertion is reported to be homogeneous without pulverization like in the crystalline material $[13,14]$. This view is not supported by all the authors [24] but recent studies have demonstrated that the amorphous Si thin film electrodes showed improved electrochemical performance [12,19,25-30]. As far as applications are concerned, these films are too thin $(<500 \mathrm{~nm})$ to provide sufficient capacity and the way to expand the film thickness without sacrificing cycleability and specific capacity constitutes an important issue. Only a few recent encouraging data are available for thick films. The best results are found for films, in the range 1-5 J.Lm thick, deposited on Cu by vacuum deposition [19] or chemical vapour deposition [29,30], and by electron-beam deposition [31]. Capacities available with those thicker films and included in the realm 1200-1500 $\mathrm{mAh} \mathrm{g}^{-1}$ can be stabilized over 100-200 cycles while stability for larger capacities does not exceed ten to a few tenths of cycles [32]. In fact, to date, no research group has definitively established that the theoretical capacity can be stabilized over a large number of cycles.

A new approach consists in using a three-dimensional architecture which allows combining the accommodation of the large volume changes expected for $\mathrm{Li}$ insertion in crystalline silicon with a continuous and efficient electrical contact between $\mathrm{Si}$ particles. Porous silicon electrodes have been considered and tested in this way $[33,34]$. In the same frame of mind, Si nanowires as an emerging structure, offers advantages of large surface to ratio volume, efficient electron conducting pathways, shorter diffusion pathways for lithium and facile strain relaxation, what let us believe that silicon nanowires (SiNWs) could be a potential candidate to optimize the electrochemical performance of the Si negative electrode and to replace carbonaceous materials. Si nanowires (SiNWs) are a new class of materials currently studied within the context of molecular electronics. Typically, the diameter of such nanowires range between a few $\mathrm{nm}$ and few hundreds of nanometers. As they exhibit excellent electrical characteristics, nanowire-based transistors could replace classical CMOS devices in the near future [35].

To date and to the best of our knowledge, no paper deals with electrochemical characteristics of SiNWs as anodic material for a Li-ion battery. Actually, only the structural changes of this nanostructured material have already been investigated (for doping and contacting purposes) by high-resolution electron microscopy at different lithium alloying/de-alloying levels controlled by an electrochemical method [36].

In this work we demonstrate for the first time the feasibility of using Si nanowires as negative electrode for Li-ion batteries, which opens up a new field of research for the development of the microbatteries.

\section{Experimental}

SiNWs are synthesized by chemical vapour deposition (CVD) according to the vapour-liquid-solid (VLS) growth mechanism which has been extensively studied $\sim 40$ years ago by Wagner [37] for the growth of whiskers. This mechanism can be explained with the help of Fig. 1. A Si bearing gas (e.g. $\mathrm{SiH}_{4}$ ) is allowed to flow over catalyst clusters (e.g. Au) deposited on a chemically inert substrate which is heated above the catalyst-Si eutectic melting temperature. Some $\mathrm{SiH}_{4}$ molecules decompose by pyrolysis and some of the released $\mathrm{Si}$ atoms adsorb on the catalyst dots and alloy with the surface atoms. As more $\mathrm{Si}$ is brought to the catalyst surface, the alloy composition evolves towards the eutectic composition. Melting starts to occur (Fig. 1a), rapidly consuming the whole catalyst dot. Continued feed of Si makes the alloy composition evolve towards saturation, inducing Si precipitation. An equilibrium is

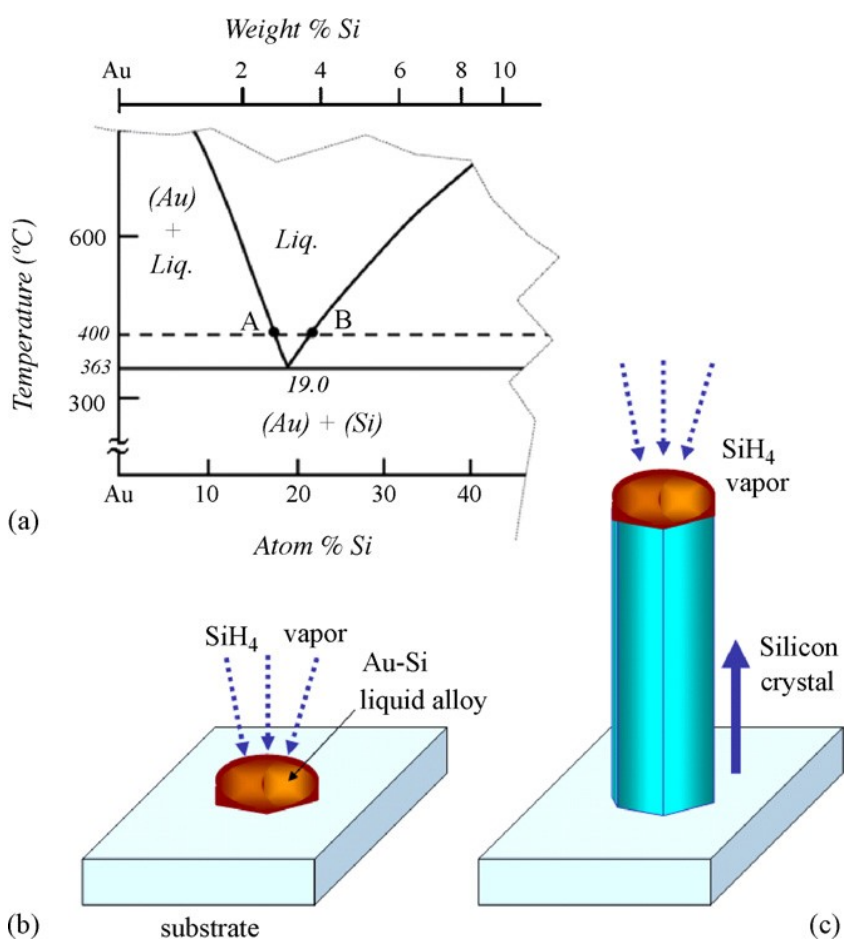

Fig. 1. Schematic mechanism of the VLS growth process: (a) the Au-Si phase diagram on the Au-rich side. (b and c) Formation of the liquid drop and growth of the Si whisker (see text for more details).

rapidly reached, where the flux of $\mathrm{Si}$ atoms incorporated at the surface of the liquid alloy is balanced by the flux of Si atoms precipitating at the liquid-solid interface. As the liquid surface behaves as an ideally rough surface, the sticking coefficient of the gaseous $\mathrm{SiH}_{4}$ molecules is close to 1 , resulting in a highly anisotropic growth that explains the whisker shape obtained (Fig. 1c). The Au-Si liquid drop rises on top of the crystal and appears spherical in shape due to surface tension effects. The feasibility of Si nanowire growth by the VLS mechanism has been demonstrated recently using gold clusters [38].

The substrates used in this study were commercial stainless steel (316 L) foils of $50 \mathrm{~J} . \mathrm{Lm}$ thickness. Prior to CVD growth of SiNWs, $50 \mathrm{~nm}$ of $\mathrm{Ti}$ as an adhesive layer and $100 \mathrm{~nm}$ of TiN as a conductive diffusion barrier were deposited on the substrates, followed by a $10 \mathrm{~nm}$-thick Au film, using a magnetron sputtering system. The substrates were then loaded in a CVD furnace and heated under vacuum (base pressure less than $10^{-5}$ mbar) above the Au-Si eutectic melting temperature (in this study, we used three different temperatures, namely 525, 550 and $575{ }^{\circ} \mathrm{C}$ ). During this treatment, the Au thin film transforms into clusters of various sizes, in order to reduce the superficial/interfacial energy with $\mathrm{TiN}$. Then, $\mathrm{SiH}_{4}$ diluted at $5 \%$ in hydrogen $\left(\mathrm{H}_{2}\right)$ is injected in the furnace for $15 \mathrm{~min}$ at a total flow of $100 \mathrm{sccm}$ and total pressure of $15 \mathrm{mbar}$.

Electrochemical studies were carried out in a two-electrode cell (Swagelok ${ }^{\circledR}$ type). This cell was prepared inside a dry box by placing a clean lithium metal disk (7 mm diam.), a glass fiber separator soaked with the electrolyte solution, and the cathode film $\left(0.28 \mathrm{~cm}^{2}\right)$ into a Teflon container with two stainless steel terminals. The electrolyte used was $1 \mathrm{~mol} \mathrm{~L}{ }^{-1} \mathrm{LiClO}_{4}$, dried under vacuum at $180{ }^{\circ} \mathrm{C}$ for $15 \mathrm{~h}$, dissolved in twice-distilled propylene carbonate obtained from Fluka. Galvanostatic measurements were made with a computer controlled 1470 A Solartron potentiostat. A constant current density of $35 \mathrm{~J} . \mathrm{LA} \mathrm{cm} \mathrm{cm}^{-2}$ was used for charge-discharge experiments. 


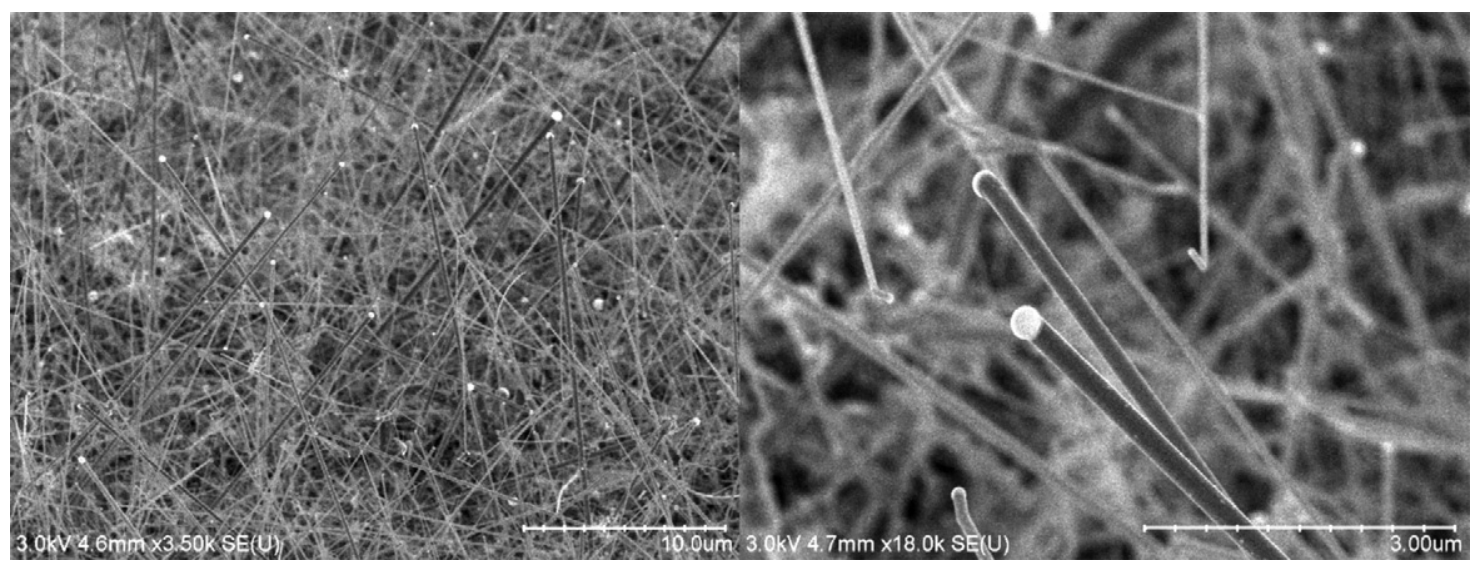

Fig. 2. SEM observations of SiNWs films obtained at $550^{\circ} \mathrm{C}$.

\section{Results and discussion}

A SEM image of the thin SiNWs grown at $550{ }^{\circ} \mathrm{C}$ is displayed in Fig. 2. It can be seen that SiNWs with diameters up to $300 \mathrm{~nm}$ are uniformly obtained on the surface of the TiN-covered substrate. The small Au droplets used as catalyst for the growth of Si wires and whose size mainly controls their diameter are still present and they can be observed at the top of the nanowires.

The Raman spectrum of the as-deposited SiNWs is shown in Fig. 3. A well defined and symmetric peak at $520.1 \mathrm{~cm}^{-1}$ corresponding to the first order Raman line for crystalline silicon is observed which ascertains very well crystallized SiNWs are prepared [39].

Before testing the SiNWs as active electrode material against Li alloying, we have evaluated the possible electrochemical contribution of the Au droplets still present at the top of the silicon wires after synthesis. Indeed even when only a little is known on the electrochemical properties of $\mathrm{Li}-\mathrm{Au}$ alloys at room temperature, the Au electrode has been recently proved to accommodate $\mathrm{Li}$ in the $0.02-0.5 \mathrm{~V}$ potential range with a poor reversibility $[40,41]$. The discharge-charge curves obtained for a $50 \mathrm{~nm}$ thick gold film are shown in Fig. 4. Two voltage plateaus corresponding to the $\mathrm{Li}$ alloying process into two different phases are observed at 0.2 and $0.1 \mathrm{~V}$ while Li removal from the alloy takes place in two steps at 0.18 and $0.4 \mathrm{~V}$ in good agreement with Refs. [40,41]. The poor efficiency of the charge process is clearly evidenced since only $50 \%$ of the faradaic yield involved in the alloying reaction is recovered at

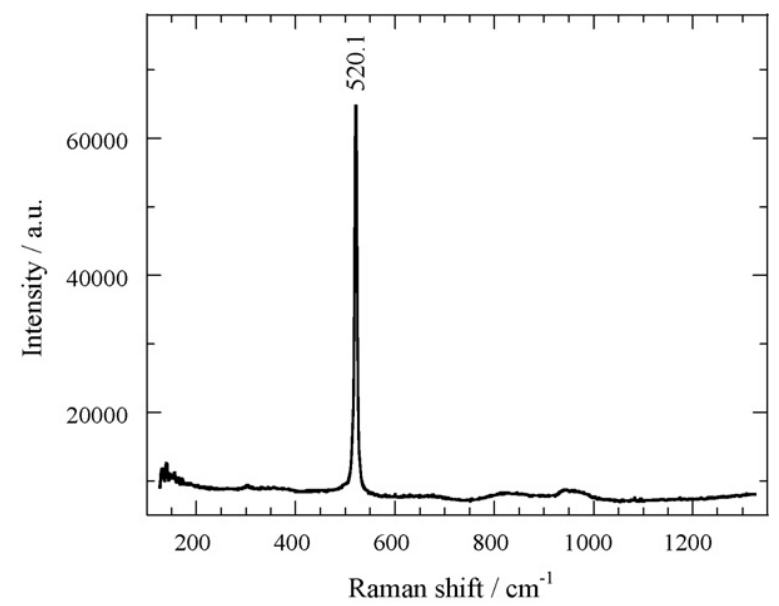

Fig. 3. Raman spectrum of SiNWs films obtained at $550^{\circ} \mathrm{C}$.

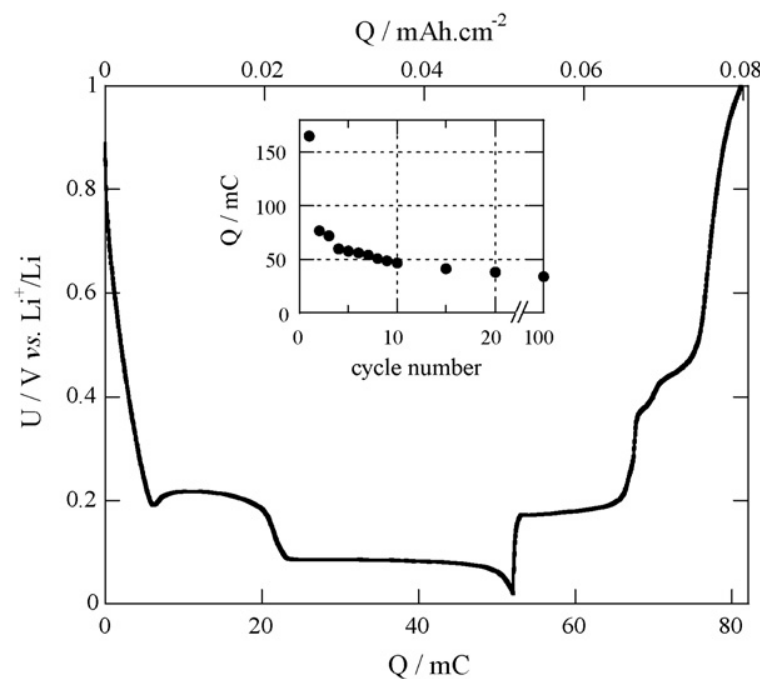

Fig. 4. Typical voltage curve of a $50 \mathrm{~nm}$ thick gold film discharged/charged between 0.02 and $1 \mathrm{~V}$ and the capacity vs. cycle number for a $10 \mathrm{~nm}$ thick gold film in the inset.

$1 \mathrm{~V}$. For a $10 \mathrm{~nm}$ thick gold film, as used here for the SiNWs growth, the evolution of the capacity obtained during the cycling experiments as a function of cycle number is reported in the inset of Fig. 4. At $35 \mathrm{~J} . \mathrm{LA} \mathrm{cm}^{-2}$, the coulombic charge drastically decreases from $170 \mathrm{mC}$ to reach a few tenths of $\mathrm{mC}$ after less than 15 cycles.

The electrochemical properties of SiNWs have been studied for different temperature of deposition. The typical discharge-charge curves presented in Fig. 5 (cycles 1, 2, 5 and 10) are related to a sample deposited at $525{ }^{\circ} \mathrm{C}$. A part of the coulombic charge involved for potentials upper than $0.5 \mathrm{~V}$ during the first reduction is usually ascribed to the formation of a solid electrolyte interphase (SEI) stemming from the decomposition products of the liquid electrolyte. This irreversible phenomenon depends on the silicon surface which can be covered with a native layer consisting of silicon oxide (-Si-O-Si-) and silanol $(-\mathrm{Si}-\mathrm{OH})[42]$ and the corresponding capacity equals in this case about $150 \mathrm{mC}$. At lower potentials, the initial lithiation of crystalline silicon results in a single low voltage plateau located at $0.15 \mathrm{~V}$. From literature data on the electrochemical reaction of lithium with silicon, according to the equilibrium Li-Si phase diagram, four distinct open circuit voltage (OCV) curves corresponding to the successive formation of $\mathrm{Li}_{12} \mathrm{Si}_{7}$, $\mathrm{Li}_{7} \mathrm{Si}_{3}, \mathrm{Li}_{13} \mathrm{Si}_{4}, \mathrm{Li}_{21} \mathrm{Si}_{5}$ could be expected [9,43]. Due to the very close corresponding OCV values, only one process can be discerned at 


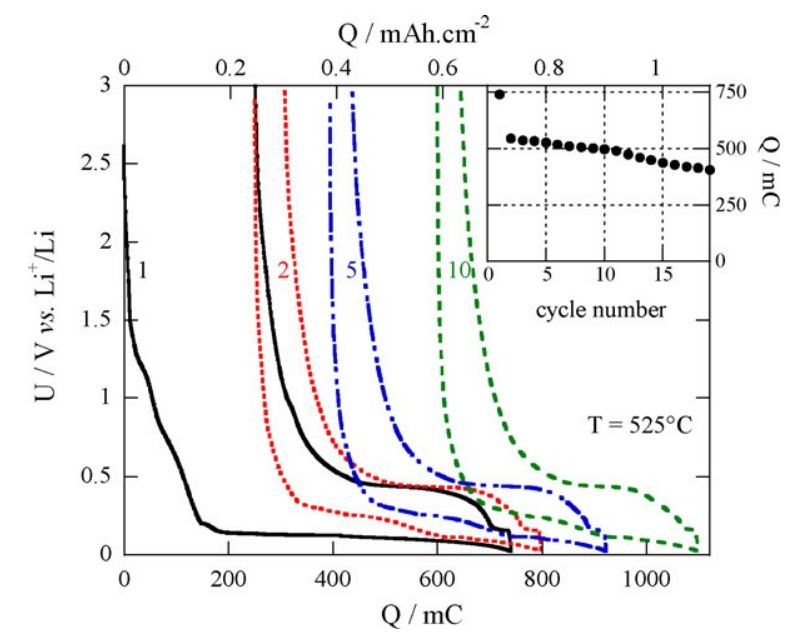

Fig. 5. Voltage curves of a SiNWs film obtained at $525^{\circ} \mathrm{C}$ discharged/charged between 0.02 and $3 \mathrm{~V}$ (cycles $1,2,5,10$ ) and the corresponding capacity vs. cycle number in the inset.

constant current. According to recent galvanostatic studies [44,45], the $0.15 \mathrm{~V}$ voltage plateau observed in Fig. 5 could correspond to the lithiation of crystalline Si leading to an amorphous a- $\mathrm{Li}_{\mathrm{x}} \mathrm{Si}$ phase. At the end of the discharge, i.e. for $\mathrm{Q}>700 \mathrm{mC}$ (Fig. 5), the crystalline $\mathrm{Li}_{13} \mathrm{Si}_{4}$ phase could be formed as suggested by a very recent study performed on crystalline silicon powder [46].

The delithiation reaction mainly results in a voltage plateau at $0.45 \mathrm{~V}$ corresponding to the formation of silicon. From the second cycle, two reduction steps are observed at 0.25 and $0.1 \mathrm{~V}$, whereas the oxidation keeps the same profile as during the first cycle. As a conclusion, these preliminary electrochemical data are in a good agreement with those known for the reversible Li alloying/dealloying reaction in crystalline silicon [44-46]. In other respects, it can be pointed out that the two small reduction and oxidation steps at, respectively, 0.2 and $0.16 \mathrm{~V}$ probably reveal the contribution of the $\mathrm{Li}-\mathrm{Au}$ system resulting from the Au droplets at the top of the nanowires. Nevertheless, our previous experiments performed on Au films show that this contribution cannot exceed $40 \mathrm{mC}$ at the best, i.e. $\sim 10 \%$ of the capacity (inset in Fig. 4).

Without taking into account the loss of capacity ascribed to the SEI formation, the inset in Fig. 5 demonstrates that a satisfactory

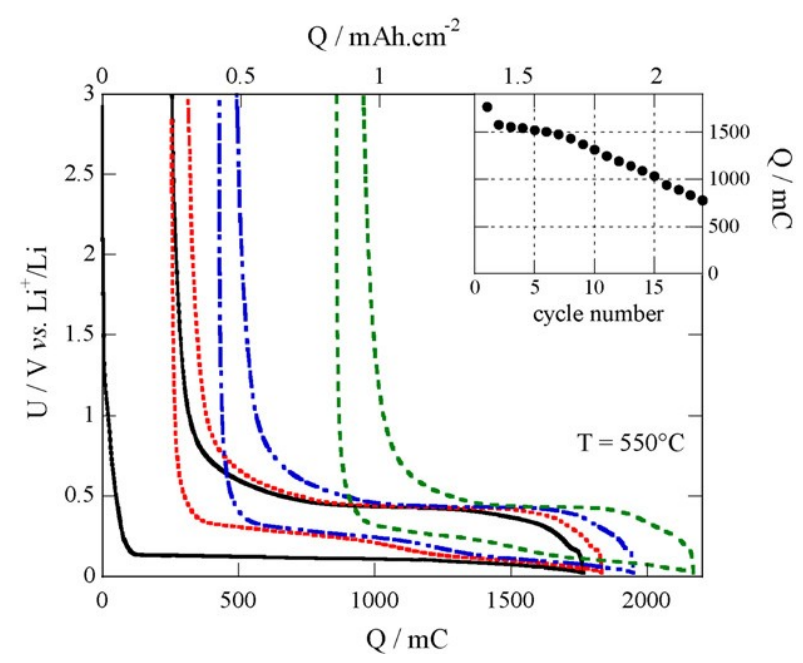

Fig. 6. Voltage curves of a SiNWs film obtained at $550{ }^{\circ} \mathrm{C}$ discharged/charged between 0.02 and $3 \mathrm{~V}$ (cycles $1,2,5,10$ ) and the corresponding capacity vs. cycle number in the inset.

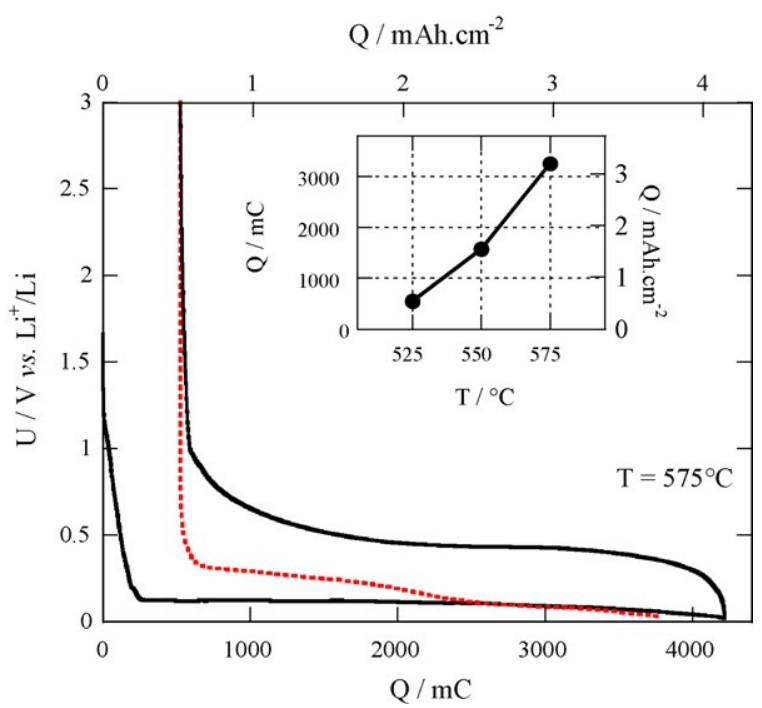

Fig. 7. Voltage curves of a SiNWs film obtained at 575 ' $\mathrm{C}$ discharged/charged between 0.02 and $3 \mathrm{~V}$ (cycle 1 in dark line, second reduction in dashed line) and the capacity vs. SiNWs deposition temperature in the inset.

capacity retention can be achieved with SiNWs since $400 \mathrm{mC}$ are still available after 20 cycles.

The electrochemical behaviour of the sample synthesized at $550{ }^{\circ} \mathrm{C}$ is quite the same as the sample described above except the significantly higher capacity $(1750 \mathrm{mC})$ achieved in the same voltage range (Fig. 6). This could be related to an increase of the SiNWs growth rate at higher temperature leading to a greater amount of deposited Si. A slow decline of the faradaic yield with cycles is observed but more than $750 \mathrm{mC}$ are still available after 20 cycles.

The capacity value can still be increased as shown by the electrochemical behaviour of a sample with SiNWs grown at $575{ }^{\circ} \mathrm{C}$ (Fig. 7). Indeed, without taking into account irreversible capacity in the first cycle (same order of magnitude whatever the temperature of growth of SiNWs), a capacity as high as $3200 \mathrm{mC}$, i.e. around $3000 \mathrm{~J} . \mathrm{LAh} \mathrm{cm}^{-2}$ is reached with a satisfactory efficiency of the charge process. Such an attractive electrochemical behaviour makes it possible to use SiNWs in secondary Li microbatteries based on thin film metal oxides as positive electrodes and characterized, for thick films, by capacities of about 250-300 J.LAh cm ${ }^{-2}$ at best. The quasi-linear relationship between capacity and SiNWs synthesis temperature indicates a possible control of the effective Si surface deposit during the growth process and suggests that an

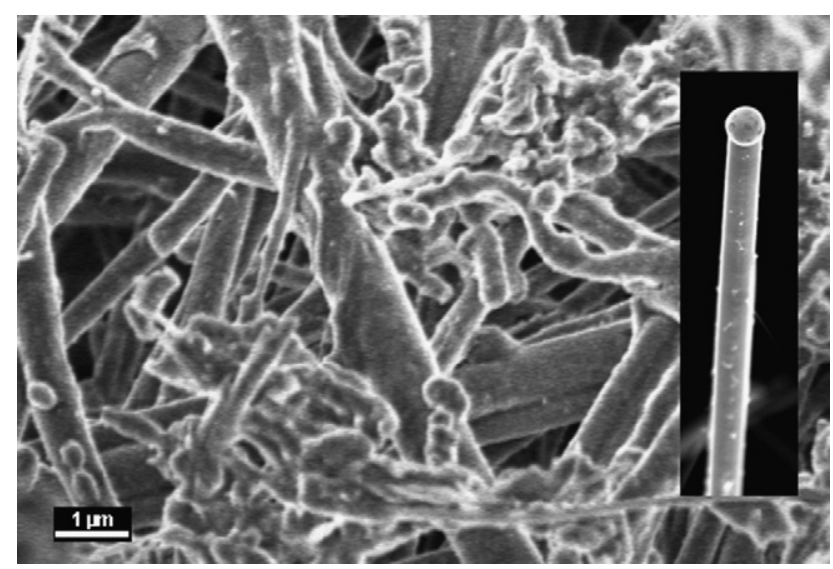

Fig. 8. SEM images (same magnification) of unlithiated SiNWs (inset) and fully lithiated SiNWs. 
optimization of the capacity is possible. The influence of several parameters like the length and the diameter of the SiNWs, the density of the deposit and their crystallinity must be considered in details, making possible a future application of SiNWs as negative electrode for rechargeable Li-ion batteries.

Moreover, a study of the modifications of the SiNWs structural morphology during both lithiation and delithiation is required in order to reveal possible damages in the 3D architecture consequently to the successive insertion/deinsertion of lithium which could be responsible of the decrease of the capacity. The SEM micrography of fully lithiated SiNWs obtained by stopping the electrochemical cycle after a full discharge, i.e. at $0.02 \mathrm{~V}$, is presented in Fig. 8 and compared to the micrography of the starting material (inset). As expected, statically, wires seem to be larger in diameter when they are lithiated. A further complete study in under progress to determine the size distribution of the SiNWs and the average diameter, for different amounts of lithium inserted in the wires during both the discharge and the charge, for successive cycles.

\section{Conclusion}

In this paper, we have reported the first electrochemical results on the use of SiNWs as negative electrode for rechargeable lithium microbatteries. Until now and to the best of our knowledge, such results have never been reported in the literature. We have shown that SiNWs constitute a new possibility for building a threedimensional negative electrode of great interest for rechargeable $\mathrm{Li}$ microbatteries. The SiNWs electrochemical behaviour resembles that known for crystalline silicon. It presents an attractive working potential $\left(<0.5 \mathrm{~V}\right.$ vs. $\left.\mathrm{Li}^{+} / \mathrm{Li}\right)$ and large storage capacities (a few thousands of $\mathrm{mC}$ ). Though the reversible Li alloying/dealloying is ensured right now on more than ten cycles with good charge-discharge efficiency, a significant decrease of the capacity takes place with further cycling. We have also shown that the available storage capacity strongly depends on the SiNWs growth temperature and increases with it. These preliminary and promising results call for a further insight into the Li alloying/de-alloying mechanism in order to investigate and to understand both the electrochemical and structural response of SiNWs vs. Li content, the discharge-charge rate, cycling.

\section{Acknowledgment}

This work was partially supported by the French ANR contract "NANOBAT2".

\section{References}

[1] G.-A. Nazri, G. Pistoia, in: G. Pistoia (Ed.), Lithium batteries : Science and Technology, Kluwer Academic Publishers, 2004, p. 113

[2] J.M. Tarascon, M. Armand, Nature 414 (2001) 359.

[3] J.L. Tirado, Mater. Sci. Eng. R 40 (2003) 103.

[4] M. Winter, J.O. Besenhard, Electrochim. Acta 45 (1999) 31.

[5] J.O. Besenhard, J. Yang, M. Winter, J. Power Sources 68 (1997) 87.
[6] L.Y. Beaulieu, K.W. Eberman, R.L. Turner, L.J. Krause, J.R. Dahn, Electrochem. Solid State Lett. 4 (2001) A137.

[7] W.G. Moffat, The Handbook of Binary Phase Diagrams, Genium Publishing Corp., Schenectady, New York, 1990.

[8] J.O. Besenhard, in: T. Besenhard (Ed.), Handbook of Battery Materials, WileyVCH, Weiheim, 1999, p. 363.

[9] W.J. Weydanz, M. Wohlfahrt-Mehrens, R.A. Huggins, J. Power Sources 81-82 (1999) 237.

[10] M. Winter, J.O. Besenhard, M.E. Spahr, P. Novak, Adv. Mater. 10 (1998) 725.

[11] Y. Kubota, M.C.S. Escano, H. Nakanishi, H. Kasai, J. Alloy Compd. 434-435 (2007) 294.

[12] S. Ohara, J. Suzuki, K. Sekine, T. Takamura, J. Power Sources 119-121 (2003) 591

[13] T.D. Hatchard, J.R. Dahn, J. Electrochem. Soc. 151 (2004) A838.

[14] L.Y. Beaulieu, T.D. Hatchard, A. Bonakdarpour, M.D. Fleischauer, J.R. Dahn, J. Electrochem. Soc. 150 (2003) A1457.

[15] J.W. Kim, J.H. Ryu, K.T. Lee, S.M. Oh, J. Power Sources 147 (2005) 227.

[16] M. Yoshio, H. Wang, K. Fukuda, T. Umeno, N. Dimov, Z. Ogumi, J. Electrochem. Soc. 149 (2002) A1598.

[17] W.-R. Liu, J.-H. Wang, H.-C. Wu, D.-T. Shieh, M.-H. Yang, N.-L. Wu, J. Electrochem. Soc. 152 (2005) A1719.

[18] H.X. Deng, C.Y. Chung, Y.T. Xie, P.K. Chu, K.W. Wong, Y. Zhang, Z.K. Tang, Surf. Coat. Technol. 201 (2007) 6785.

[19] T. Takamura, M. Uehara, J. Suzuki, K. Sekine, K. Tamura, Power Sources J. 158 (2006) 1401

[20] Y. Liu, K. Hanai, J. Yang, N. Imanishi, A. Hirano, Y. Takeda, Electrochem. Solid State Lett. 7 (2004) A369.

[21] M. Yoshio, T. Tsumura, N. Dimov, J. Power Sources 146 (2005) 10.

[22] M.K. Datta, P.N. Kumta, J. Power Sources 158 (2006) 557.

[23] L.Y. Beaulieu, K.C. Hewitt, R.L. Turner, A. Bonakdarpour, A.A. Abdo, L. Christensen, K.W. Eberman, L.J. Krause, J.R. Dahn, J. Electrochem. Soc. 150 (2003) A149.

[24] S. Bourderau, T. Brousse, D.M. Schleich, J. Power Sources 81-82 (1999) 233.

[25] T. Takamura, S. Ohara, M. Uehara, J. Suzuki, K. Sekine, J. Power Sources 129 (2004) 96

[26] V. Baranchugov, E. Markevich, E. Pollak, G. Salitra, D. Aurbach, Electrochem. Commun. 9 (2007) 796.

[27] T.L. Kulova, A.M. Skundin, Y.V. Pleskov, E.I. Terukov, O.I. Kon’kov, J. Electroanal. Chem. 600 (2007) 217.

[28] H. Guo, H. Zhao, C. Yin, W. Qiu, Mater. Sci. Eng. 131 (2006) 173.

[29] T. Yoshida, T. Fujihara, H. Fujimoto, R. Ohshita, M. Kamino, S. Fujitani, Abstract No 48, Proceedings of the 11th IMLB, Monterey, CA, June 23-28, 2002.

[30] I. Yonezu, H. Tarui, S. Yoshimura, S. Fujitani, T. Nohma, Abstract No 58, Proceedings of the 12th IMLB, Nara, Japan, June 27-July 2, 2004.

[31] J. Yin, M.W. Koichi Yamamoto, Y. Kitano, S. Tanase, T. Sakai, J. Electrochem. Soc. 153 (2006) A472.

[32] J.P. Maranchi, A.F. Hepp, P.N. Kumta, Electrochem. Solid State Lett. 6 (2003) A198.

[33] H.-C. Shin, J.A. Corno, J.L. Gole, M. Liu, J. Power Sources 139 (2005) 314.

[34] M. Green, E. Fielder, B. Scrosati, M. Wachtler, J.S. Moreno, Electrochem. Solid State Lett. 6 (2003) A75.

[35] Y. Cui, Z. Zhong, D. Wang, W.U. Wang, C.M. Lieber, Nano Lett. 3 (2003) 149.

[36] G.W. Zhou, H. Li, H.P. Sun, D.P. Yu, Y.Q. Wang, X.J. Huang, L.Q. Chen, Z. Zhang, Appl. Phys. Lett. 75 (1999) 2447.

[37] R.S. Wagner, in: A.L. Svitt (Ed.), Whisker Technology, Wiley Intersciences, New York, 1970, p. 47.

[38] Y. Cui, L.J. Lauhon, M.S. Gudiksen, J. Wang, C.M. Lieber, Appl. Phys. Lett. 78 (2001) 2214.

[39] J. Niu, J. Sha, Z. Liu, Z. Su, J. Yu, D. Yang, Physica E 24 (2004) 268.

[40] G. Taillades, N. Benjelloun, J. Sarradin, M. Ribes, Solid State Ionics 152-153 (2002) 119

[41] L. Yuan, H.K. Liu, A. Maaroof, K. Konstantinov, J. Liu, M. Cortie, J. New Mater Electrochem. Syst. 10 (2007) 95.

[42] Y.M. Lee, J.Y. Lee, H.-T. Shim, J.K. Lee, J.-K. Park, J. Electrochem. Soc. 154 (2007) A515.

[43] C.J. Wen, R.A. Huggins, J. Solid State Chem. 37 (1981) 271

[44] M.N. Obrovac, L.J. Krause, J. Electrochem. Soc. 154 (2007) A103.

[45] M.N. Obrovac, L. Christensen, Electrochem. Solid State Lett. 7 (2004) A93.

[46] J. Li, J.R. Dahn, J. Electrochem. Soc. 154 (2007) A156. 